\title{
Molecular Epidemiology of White Pine Blister Rust: Recombination and Spatial Distribution
}

\author{
R. C. Hamelin, M. Allaire, M.-J. Bergeron, M.-C. Nicole, and N. Lecours
}

Natural Resources Canada, Canadian Forest Service, Laurentian Forestry Centre, 1055 du P.E.P.S., P.O. Box 3800, Sainte-Foy, Quebec, G1V 4C7 Canada.

Accepted for publication 4 March 2005.

\section{ABSTRACT}

Hamelin, R. C., Allaire, M., Bergeron, M.-J., Nicole, M.-C., and Lecours, N. 2005. Molecular epidemiology of white pine blister rust: Recombination and spatial distribution. Phytopathology 95:793-799.

Multilocus haplotypes (MLHs) were derived for the spermogonial (monokaryotic haploid) stage of Cronartium ribicola, the causal agent of white pine blister rust. Six random amplified polymorphic DNA loci and three single-strand conformational polymorphism markers were analyzed for 246 rust samples collected from two heavily infected white pine plantations. All cankers sampled were spatially located within the plantations. The hypothesis that spores are not locally disseminated was supported by the absence of any spatial clustering in the distribution of the MLHs. A large number of MLHs was found at both sites and the haplotypic diversity was close to the maximum (one) in both populations. All measures of recombination were not different from expectations under a scenario of sexual recombination. Genetic differentiation between the two sites was very low $(\theta=0.023)$, yet it was significantly different from zero $(P<$ $0.01)$. This analysis is in agreement with a scenario of extensive sexual recombination followed by some long-distance dispersal.

Additional keywords: genetic diversity.
White pine blister rust is caused by the basidiomycete fungus Cronartium ribicola J. C. Fisch. The disease is devastating to fiveneedle pine trees, particularly in North America where it was introduced accidentally from Europe at the beginning of the twentieth century (20). This rust is heteroecious and macrocyclic: it alternates between five-needle pine trees and members of the Grossulariaceae family (which comprises Ribes spp.) to complete its life cycle (57). Mortality can reach 90 to $95 \%$ in white pine plantations (22). The disease recently has expanded its range in North America, and new introductions have been reported in new areas as well as on new hosts $(2,7,19,23,49,53)$. The recent introduction of this pathogen into natural stands of limber (Pinus flexilis) and whitebark (P. albicaulis) pine is a cause for concern given the high susceptibility of these species and their importance in the fragile ecosystems to which they belong $(25,43)$.

The use of DNA markers to generate multilocus haplotypes (MLHs) makes it possible to improve our understanding of pine rust genetics and to apply that knowledge to better understand the epidemiology of these diseases. C. quercuum $\mathrm{f}$. sp. fusiforme, the causal agent of fusiform rust, was found to comprise four metapopulations that were genetically differentiated. There was a correlation between microsatellite markers and either a longitudinal or a latitudinal gradient (31). Overall, there appeared to be a high level of genetic variability within and among these metapopulations, which is consistent with some local adaptation and limited gene flow.

In $C$. ribicola, differentiated populations were found in eastern and western North America. The low level of genetic diversity in western populations suggested that founder effects combined with a barrier to gene flow between western and the more polymorphic eastern populations were responsible for those differences (18). The North American population structure was consistent with

Corresponding author: R. C. Hamelin; E-mail address: rhamelin@nrcan.gc.ca

DOI: 10.1094/PHYTO-95-0793

(C) 2005 The American Phytopathological Society historical records showing that multiple introductions of several million seedlings from nurseries in Germany, France, and Holland were responsible for the establishment of the pathogen in eastern North America (51). By contrast, a single introduction from a French nursery was associated with the appearance of the disease in western North America. Yet, contrary to the C. quercuum f. sp. fusiforme situation, panmixis was observed within eastern and western populations with low levels of genetic differentiation among populations separated by several hundred kilometers $(8$, 15,30). This could be explained by the long-distance dispersal ability of some $C$. ribicola spores or, alternatively, by past gene flow.

At a finer scale, white pine blister rust and fusiform rust cankers sampled prior to spermatization, the process by which insects carry sexual spores (spermatia) to the receptive hyphae, were mostly represented by single multilocus haplotypes $(17,31)$. In addition, each canker sampled possessed nearly unique genetic profiles, suggesting that cankers were the result of infection by a single sexually derived basidiospore that spread vegetatively as mycelium within cankers. But $C$. ribicola and $C$. flaccidum cankers sampled at the aecial stage, following spermatization, comprised a mosaic of genetic profiles, with most of the genetic diversity within cankers being attributable to sampling among aecidia (12, 24,54). These results are consistent with the hypothesis that these rusts are highly outcrossed and that spermatization efficiently results in gene reassortment among cankers at a very fine scale.

There is much interest in using molecular genetic approaches to resolve longstanding epidemiology questions in plant pathology $(13,14,34-37)$. Cronartium pine rusts produce five different spore types. Although the roles of the different spores are fairly well known, much remains to be discovered concerning their actual epidemiological importance. One question that remains largely unresolved is the distance at which each of these spores can be dispersed and their relative importance in dissemination. The number of uredinia on oak was reduced by $90 \%$ at a distance of 3.1 to $152.4 \mathrm{~m}$ from the source. The preponderance of aeciospores deposited near the source suggested that local sources of aecio- 
spore inoculum were most important in the fusiform rust epidemic (45). Similarly, disease gradients dropped sharply between 10 and $1,000 \mathrm{~m}$ between the pine and the intermediate host in C. flaccidum (42). Nevertheless, in experiments using oak-free borders and oak controls within sites, rust incidence was greater in oak-free areas compared with ones with oak (46), thus suggesting dispersal of inoculum further than the 152-m border.

By studying the allelic distribution at several well-characterized loci in intensively sampled populations and recording the spatial coordinates of the cankers sampled, it may be possible to address these questions using a different approach. Testing for spatial patterns and looking for the signature of recombination or linkage disequilibrium may help infer the mode and distance of dissemination as well as the spore type involved. In white pine blister rust, if primary inoculum for pine infection is produced and disseminated locally, some spatial clustering of allelic distribution would be expected when sampling the spermogonial spore stage on pine. Alternatively, long-distance dispersal would result in homogenization of allelic distribution within and among sites; little or no correlation between spatial distance and genetic similarity at the local scale would be expected if this were the case.

Primary infection of $C$. ribicola on the pine host in heteroecious pine rusts originates from basidiospores produced on the telial host. Because basidiospores are derived from meiosis, the pattern of multilocus polymorphism should have the signature of recombination and unlinked loci should be in equilibrium. To observe this, samples should be collected directly from the spermogonia before cankers are spermatized $(16,17,31)$. Basidiospores are not known to re-infect the telial host or spread through secondary asexual cycles; therefore, cankers prior to spermatization should contain individuals that are the result of sexual reproduction without introduced bias from asexual cycles. Inbreeding or selection could result in a departure from the expectation of linkage equilibrium.

So far, sampling of $C$. ribicola for population studies has been reported with large geographic representation but with relatively small sample size per site $(12,15,17,18,54)$. Also, no particular effort has been made to record the spatial distribution of samples within sites. The objectives of this study were to test the hypothesis that $C$. ribicola multilocus haplotypes derived from the spermogonial stage on the pine host follow a random spatial distribution and that there is no nonrandom genetic association.

\section{MATERIALS AND METHODS}

Sampling. Two eastern white pine (Pinus strobus L.) plantations $42 \mathrm{~km}$ apart were intensively sampled and the cankers were mapped. Both sites were planted with unselected seed lots. The Saint-Cyprien site $\left(-70^{\circ} 13^{\prime} 45.793^{\prime \prime}\right.$ longitude, $46^{\circ} 22^{\prime} 46.289^{\prime \prime}$ latitude) was planted in 1982 with $\approx 5,000$ white pine trees on 2.5 ha. Sampling was done on 22 July 1997 and on 14 July 1998, as described previously (17). The Saint-Georges-de-Beauce site $\left(-70^{\circ} 36^{\prime} 34.079^{\prime \prime}\right.$ longitude, $46^{\circ} 05^{\prime} 36.658^{\prime \prime}$ latitude) is a white pine plantation of $\approx 1$ ha planted with 2,300 trees in 1990 . Samples were collected on 16 and 17 July 1998. Total number of samples collected was 128 at Saint-Cyprien and 118 at SaintGeorges. Spermatia were harvested by piercing closed spermogonial blisters with the tip of a Pasteur pipette and collecting the nectar in $1.5-\mathrm{ml}$ microtubes containing $1.5 \mathrm{M}$ sorbitol. Samples were kept on ice until processed.

DNA extraction. Prior to DNA extraction, sorbitol-collected spermatia were pelleted at 13,000 rpm for $7 \mathrm{~min}$, washed with $100 \mu \mathrm{l}$ of extraction buffer $(100 \mathrm{mM}$ Tris- $\mathrm{HCl}, \mathrm{pH} 9.5,2 \%$ cetyltrimethylammonium bromide, $1.4 \mathrm{M} \mathrm{NaCl}, 1 \%$ polyethylene glycol 8000, 20 mM EDTA, pH 8.0, 0.25\% $\beta$-2-mercaptoethanol), and pelleted once again before lyophilization. DNA was extracted using a modified version of the method described previously (8). Desiccated spores were ground with an equivalent amount of diatomaceous earth in $100 \mu \mathrm{l}$ of extraction buffer, with a pestle fixed to a rotor $(1,300 \mathrm{rpm}, 3 \mathrm{~min})$. Additional extraction buffer $(300 \mu \mathrm{l})$ was added and the homogenized mixture was incubated at $65^{\circ} \mathrm{C}$ for $1 \mathrm{~h}$ and vortexed briefly every $15 \mathrm{~min}$. The samples were extracted with phenol/chloroform/isoamyl alcohol (25:24:1), vortexed, and centrifuged at 13,000 rpm for $10 \mathrm{~min}$. The aqueous phase was collected and DNA was precipitated by adding sodium acetate and isopropanol. After an incubation of $1 \mathrm{~h}$ at $-20^{\circ} \mathrm{C}$, the DNA was pelleted by centrifuging for $10 \mathrm{~min}$ at $13,000 \mathrm{rpm}$ and washed with $70 \%$ ethanol. The pellet was dried, resuspended in 20 to $40 \mu \mathrm{l}$ of Tris-EDTA (TE) buffer (10 mM Tris-HCl, $\mathrm{pH} 8.0$, $1 \mathrm{mM}$ EDTA, $\mathrm{pH} 8.0$ ), and heated to $55^{\circ} \mathrm{C}$ for $15 \mathrm{~min}$. DNA was diluted from 1:20 to 1:50, depending on DNA concentration.

Random amplified polymorphic DNA. Random amplified polymorphic DNA (RAPD) amplifications were performed in re-

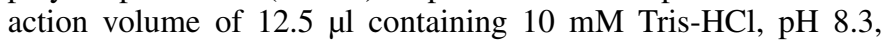
$50 \mathrm{mM} \mathrm{KCl}, 2.5 \mathrm{mM} \mathrm{MgCl} 2,200 \mu \mathrm{M}$ each dNTP (Amersham Biosciences Corp., Piscataway, NJ), $0.2 \mu \mathrm{M}$ oligonucleotide (QIAGEN, Alameda, CA), 0.5 unit of Taq DNA polymerase (Roche Diagnostics Corp., Indianapolis, IN), and $1 \mu \mathrm{l}$ of genomic DNA ( $\approx 5 \mathrm{ng}$ ). The thermal cycler (model PTC-100; MJ Research Inc., Watertown, MA) was programmed for a denaturation step at $94^{\circ} \mathrm{C}$ for $1 \mathrm{~min}$ followed by 40 cycles at $94^{\circ} \mathrm{C}$ for $5 \mathrm{~s}$ and $35^{\circ} \mathrm{C}$ for $10 \mathrm{~s}$; followed by an elevation of $0.3^{\circ} \mathrm{C} / \mathrm{s}$ to reach $72^{\circ} \mathrm{C}$, then $72^{\circ} \mathrm{C}$ for $30 \mathrm{~s}$; followed by an elevation of $0.2^{\circ} \mathrm{C} / \mathrm{s}$ to reach $94^{\circ} \mathrm{C}$. The reaction ended with a $4-\mathrm{min}$ extension step at $72^{\circ} \mathrm{C}$. The selected primers OPA01, OPC08, OPE15, OPK11, and OPK19 yielded one or more repeatable polymorphisms $(8,15,17,18)$. Amplification products were separated by electrophoresis on $1.5 \%$ agarose gel using $1 \times$ Tris-acetate-EDTA (TAE) buffer. DNA was visualized by UV radiation after ethidium bromide staining.

Polymerase chain reaction single-strand conformational polymorphism. Three co-dominant markers were selected to identify single-strand conformational polymorphism (SSCP): Cro $r$ II (56), CrA9, and CrME. For each of these loci, a pair of primers was designed: Cr-148f (5'-TTGGGTAGCGTGATCGGTAT-3')/ Cr-554rc (5'-CGACCAAGGTAAGCTTCTGC-3'), CrA9-137f (5'-CAACAGCTCGCCGTGAACTG-3')/CrA9-432rc (5'-GGGTAACGCCGCTCGTGATAAC-3'), and CrME-359f (5'-GACTGGCTCAATTTCTTTCC-3')/CrME-820rc (5'-CATATGTGGTTGGGTGAATGA-3'). All amplifications were carried out in a thermal cycler (model PTC-100; MJ Research Inc.), in a 25- $\mu$ reaction volume containing $10 \mathrm{mM}$ Tris- $\mathrm{HCl}, \mathrm{pH} 8.3,50 \mathrm{mM} \mathrm{KCl}$, $1.5 \mathrm{mM} \mathrm{MgCl} 2,200 \mu \mathrm{M}$ each dNTP (Amersham Biosciences Corp.), $1 \mu \mathrm{M}$ each oligonucleotide (Université Laval, Quebec, Canada), 1 unit of Taq DNA polymerase (Roche Diagnostics Corp.), and $2 \mu \mathrm{l}$ of genomic DNA ( $\approx 10 \mathrm{ng})$. The thermocycling conditions for Cro $r$ II were initiated by a denaturation step of $3 \mathrm{~min}$ at $94^{\circ} \mathrm{C}$ followed by 35 cycles of $30 \mathrm{~s}$ at $94^{\circ} \mathrm{C}, 30 \mathrm{~s}$ at $55^{\circ} \mathrm{C}$, and $2 \mathrm{~min}$ at $68^{\circ} \mathrm{C}$; a final extension step of $8 \mathrm{~min}$ at $68^{\circ} \mathrm{C}$ ended the reaction. For CrA9 and CrME loci, the annealing of primers was done at $58^{\circ} \mathrm{C}$ for $1 \mathrm{~min}$.

For SSCP analysis, $5 \mu$ l of polymerase chain reaction (PCR) products were mixed with $3 \mu$ l of Bagley's (1) buffer ( $0.05 \%$ bromophenol blue, $0.05 \%$ xylene cyanol in formamide), denatured at $100^{\circ} \mathrm{C}$ for $3 \mathrm{~min}$, and snap cooled on ice. Samples were applied to a nondenaturing polyacrylamide-like gel, containing $0.8 \times \mathrm{MDE}$ gel solution (Cambrex Bio Science Rockland Inc., Rockland, ME) and $0.6 \times$ Tris-borate-EDTA (TBE) buffer. Gel was poured with a peristaltic pump onto 260 -by-125-mm glass plates, spaced by a 0.5-mm U-frame (Amersham Biosciences AB, Uppsala, Sweden). Gel Bond PAG film (Amersham Biosciences AB) was inserted between plates to hold the gel. Horizontal electrophoresis was performed with the LKB Multiphor II system (Amersham Biosciences $\mathrm{AB}$ ), with $0.6 \times \mathrm{TBE}$ as running buffer. Constant temperature was ensured by the LKB Multitemp II thermostatic circulator and the LKB ECPS 3000/150 was used as a power supply (Amersham Biosciences AB). Kerosene was dropped on the 
ceramic cooling plate to provide thermal uniformity to the gel. Specific running conditions, including temperature, electrical power, and migration time, were empirically determined for each of three SSCP loci: Cro $r$ II $\left(4^{\circ} \mathrm{C}, 8 \mathrm{~W}, 18 \mathrm{~h}\right), \mathrm{CrA} 9\left(10^{\circ} \mathrm{C}, 2 \mathrm{~W}\right.$, $18 \mathrm{~h})$, and CrME $\left(22^{\circ} \mathrm{C}, 2 \mathrm{~W}, 18 \mathrm{~h}\right)$. After migration, DNA was visualized by silver staining using the Bio-Rad silver stain kit (Bio-Rad Laboratories, Hercules, CA), according to the manufacturer's protocol with the following modifications: all fixative steps were done without acetic acid, the duration of the two last developing steps was $2.5 \mathrm{~min}$ instead of $5 \mathrm{~min}$, and that of the stopping step was $30 \mathrm{~min}$ instead of $5 \mathrm{~min}$.

Data analysis. Direct allelic counts (present or absent) were obtained for RAPD markers from the monokaryotic spermogonia as previously described (17). For each of the three SSCP loci analyzed, alleles were scored visually according to migration profiles.

Allele frequency and gene diversity were calculated for each locus. For some analyses, samples with missing data were included (e.g., allele frequency, gene diversity, and recombination). For analyses involving multilocus haplotypes, individuals with missing data were excluded. This was the case for the spatial autocorrelation analysis.

Haplotypic diversity, defined as the probability that two individuals taken at random have different MLHs, was measured. The observed haplotypic diversity was compared with 500 random permutations to determine the proportion that was equal to or larger than the observed value (Multiloc 1.2). Two indices of recombination were calculated: the index of association $\left(\mathrm{I}_{\mathrm{A}}\right)$ and $\bar{r}_{d}$. The index of association is a measure of multilocus linkage disequilibrium $(36,47,48)$. The number of loci at which pairs of individuals differ is calculated and the variance of these distances is compared with that expected if there is no linkage disequilibrium. The $\bar{r}_{d}$ is very similar but is less dependent upon the number of loci, a potential caveat of $\mathrm{I}_{\mathrm{A}}$. It is the equivalent of a correlation coefficient of genetic distance and takes values of 0 (no linkage) to 1 (complete linkage).

The phylogenetic test for linkage disequilibrium also was used (4). The length of the most parsimonious tree fitted to the observed data set was compared with that fitted to randomized data sets, with the expectation that deviations from panmixis would lead to significantly shorter tree lengths (4).

The null hypothesis of complete panmixis was tested by generating data sets in which an infinite number of recombinations was simulated by performing 500 random permutations of the alleles amongst individuals. A $P$ value was obtained by calculating the proportion of randomization that yielded values smaller than the observed values (Multiloc 1.2).

To determine the effect of increasing the number of loci on the haplotypic diversity, a plot of the number of loci versus haplotypic diversity was generated.

Genetic differentiation between the two sites sampled was estimated by using a test of differentiation based on multilocus haplotypes similar to Weir's $F_{s t}$ (Multiloc 1.2) and by performing an analysis of molecular variance (AMOVA) (9). The null hy- pothesis of no population differentiation was tested by generating 500 data sets in which individuals were randomized across populations and calculating the proportion that was larger than the observed value.

Spatial analyses were performed by generating linear genetic and geographic distance matrices. The spatial autocorrelation procedure for multilocus data sets was used (50). A spatial correlogram was generated which showed the genetic correlation as a function of distance. Correlation values and their $95 \%$ confidence limits generated by random permutation of the data were plotted. The null hypothesis of no clustering can be rejected when the correlation values in a distance class are above or below the confidence interval. The size and number of distance classes were set manually. Fifteen distance classes of $10 \mathrm{~m}$ were set for the analysis. Decreasing the distance class resulted in too few sample sizes for the lowest class, and increasing the distance class could result in masking of local patterns. Correlation between genetic and geographic distances also was tested using a Mantel correlation test between the linear geographic and genetic distance matrices. Significance of the correlation coefficient was tested by 500 permutations of the data set.

\section{RESULTS}

In all, 246 white pine blister rust cankers were sampled in the two white pine plantations, with an average over loci of $N=$ 115.11 for Saint-Cyprien and $N=81.89$ for Saint-Georges (Table 1). Allele frequency for RAPD markers was similar to those reported previously in $C$. ribicola populations in eastern North America $(8,17)$ as well as between the two populations sampled in the current study for most markers, with some minor exceptions (e.g., marker OPE15-1600) (Table 1). Allele frequency at the three SSCP loci also was remarkably similar in the two populations sampled. There were only two alleles per locus at each of these three PCR-SSCP loci. At loci CrME, CrA9, and Cro $r$ II, the frequency of allele A was 75.9, 74.4, and 71.5\% at Saint-Cyprien, and $73.7,76.1$, and $72.5 \%$ at Saint-Georges, respectively (Table 1).

For RAPD markers, gene diversity varied widely across loci, ranging from 0.000 (i.e., complete fixation) for OPC08-750 to 0.500 for OPA01-1700 and OPK11-500 in the Saint-Cyprien plantation. Similar gene diversity was found at the Saint-Georges site (Table 1). Gene diversity at the three SSCP loci was much less variable, ranging from 0.363 for CrA9 in Saint-Georges to 0.407 for Cro $r$ II in Saint-Cyprien. Over all loci, gene diversity averaged 0.347 in Saint-Cyprien and 0.400 in Saint-Georges (Table 1).

In all, 54 and 42 MLHs were found in the Saint-Cyprien and Saint-Georges populations, respectively (Table 2). Most of these haplotypes were unique within populations and the most frequent haplotype occurred in only $5 \%$ of the samples. Haplotypic diversity was very high in both populations, with values of 0.972 in Saint-Cyprien and 0.970 in Saint-Georges. (A haplotypic diversity of 1 would be obtained if every individual possessed a unique MLH).

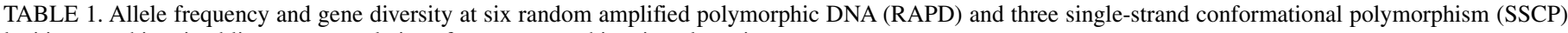
loci in two white pine blister rust populations from eastern white pine plantations ${ }^{\mathrm{a}}$

\begin{tabular}{|c|c|c|c|c|c|c|c|c|c|c|}
\hline Population $^{\mathrm{b}}$ & OPA01-1700 & OPC08-750 & OPC08-900 & OPE15-1600 & OPK11-500 & OPK19-2000 & CrME & CrA9 & Cro $r$ II & Mean \\
\hline \multicolumn{11}{|l|}{ Saint-Cyprien } \\
\hline$N$ & 111 & 115 & 114 & 115 & 105 & 116 & 116 & 121 & 123 & 115.11 \\
\hline Allele frequency & 0.468 & 1.000 & 0.219 & 0.904 & 0.495 & 0.647 & 0.241 & 0.256 & 0.285 & 0.502 \\
\hline Hs & 0.498 & 0.000 & 0.342 & 0.173 & 0.500 & 0.457 & 0.366 & 0.381 & 0.407 & 0.347 \\
\hline \multicolumn{11}{|l|}{ Saint-Georges } \\
\hline$N$ & 98 & 90 & 81 & 67 & 61 & 66 & 95 & 88 & 91 & 81.89 \\
\hline Allele frequency & 0.551 & 0.956 & 0.296 & 0.612 & 0.459 & 0.606 & 0.263 & 0.239 & 0.275 & 0.473 \\
\hline Hs & 0.495 & 0.085 & 0.417 & 0.475 & 0.497 & 0.478 & 0.388 & 0.363 & 0.399 & 0.400 \\
\hline
\end{tabular}

a The first six markers are RAPD as described previously $(8,17)$ and the last three markers are polymerase chain reaction SSCP as described in the text.

${ }^{b}$ Frequency of the null allele is reported for RAPD to keep consistency with previous reports. Hs = Nei's gene diversity (39). 
The null hypothesis of complete panmixis could not be rejected because both indices of recombination were not statistically different from zero: 0.017 and 0.013 for $\mathrm{I}_{\mathrm{A}}$ and 0.002 and 0.002 for $\bar{r}_{d}$ for Saint-Cyprien and Saint-Georges, respectively (Table 2).

Genetic differentiation between the two sampled populations was very low. A measure of genetic differentiation calculated from the MLHs, $\theta$, was 0.023 but was statistically different from $0(P<0.01)$. The AMOVA also revealed a small but significant genetic variance attributable to sampling of the two plantations $\left(\Phi_{s t}=0.030 ; P<0.01\right)$ (Table 3). Therefore, a small but statistically significant amount of diversity can be attributed to site.

The phylogenetic test for multilocus linkage disequilibrium (4) yielded observed tree lengths of 62 steps for the Saint-Cyprien population and 51 steps for the Saint-Georges population. The null hypothesis of panmixis in these populations was not rejected because the randomly generated trees were not significantly shorter than those generated by simulating recombination $(P=$ 0.33 and 0.64 for Saint-Cyprien and Saint-Georges, respectively).

The spatial analysis of haplotypes revealed no correlation between genetic and geographic distances. The spatial correlogram showed that observed correlation values in almost all distance classes were within the $95 \%$ confidence interval in both populations (Fig. 1). Changing the size of the distance classes or including haplotypes with missing data did not affect the results (data not shown). A Mantel correlation test between the genetic and distance matrices yielded small correlation coefficients $\left(R_{\mathrm{xy}}=\right.$ 0.071 in Saint-Cyprien and $R_{\mathrm{xy}}=-0.010$ in Saint-Georges). The correlation coefficient was not significantly different from zero in Saint-Georges, but was marginally positive in Saint-Cyprien.

The plot of locus versus haplotypic diversity revealed that adding more loci probably would not change the results as the haplotypic diversity progressed toward a plateau at nine loci and was close to 1 (Fig. 2). There were increases of only 2.5 and $1.7 \%$ in haplotypic diversity after the addition of the eighth and ninth loci, respectively.

\section{DISCUSSION}

Our analyses support the hypothesis of local panmixis and extensive recombination in $C$. ribicola. This result is consistent with a sexually derived inoculum source for the pine host infection and with the heterothallic nature of this pathogen. Little or no inbreeding appears to take place in this fungus as evidenced by the absence of linkage among loci and the high haplotypic diversity $(10,12,17,21)$.

Extensive sexual reproduction can have some impact on race diversity (11) and this can affect disease management, particularly in cases where resistance breeding is the control strategy. Breeding programs aimed at developing resistant genetic sources have identified resistance genes in white pine in western North America $(6,26,29)$. However, races of $C$. ribicola that can overcome resistance have been discovered in western rust populations $(27,28)$. Recombination and long-distance dispersal eventually could result in the dissemination of virulence genes in various genetic backgrounds. This could be particularly significant if the genetically differentiated eastern and western C. ribicola populations were allowed to cross (18). Intensive commercial Ribes spp. production could accelerate the appearance of a genetic bridge between eastern and western North America.

Spatial genetic structure similar to that observed here has been interpreted as the result of outcrossing and recombination. In Agaricus bisporus, another basidiomycete, spatial genetic heterogeneity was observed and no identical genotypes were found in two natural populations over 2 years of survey (55). By contrast, repeated asexual cycles or restricted dispersal would be expected to produce local genetic drift, linkage disequilibrium, or genotype clustering. Significant aggregation of mitochondrial and nuclear genotypes of Cryphonectria parasitica, the causal agent of chestnut blight, was observed and was believed to be caused by restricted dispersal within populations (38). The absence of spatial clustering and the high level of recombination observed in the current study of Cronartium ribicola is an indication that dispersal is not locally restricted and asexual propagation is not predominantly involved in the dispersal of this pathogen.

A slightly different population structure was observed for Melampsora rusts, which are also macrocyclic and heteroecious, and alternate between angiosperms and gymnosperms. Swedish populations of Melampsora larici-epitea on Salix spp. (willow), where the aecial host occurs, had a population structure consistent with sexual reproduction with higher diversity and random association among loci (44); on the other hand, UK populations had lower diversity and nonrandom association among loci $(41,44)$. In poplar leaf rust, caused by $M$. medusae, repeated cycles on the telial host resulted in departures from Hardy-Weinberg equilibrium and in linkage disequilibrium in some populations (3). In these Melampsora rusts, asexual urediospores are produced abundantly over several cycles during the summer in the northern hemisphere.

Spermatia are unlikely to be responsible for long-distance dispersal. Insect traps placed within and around the two white pine plantations sampled in the current study captured a high frequency of insect carriers of the fungus within the plantation, but none in the immediate vicinity of the plantation (40). It appears that the role of spermatia is important in the process leading to dikaryotization and that insects are attracted to nearby sporulating cankers $(5,21)$.

TABLE 2. Test of genetic recombination among six random amplified polymorphic DNA and three single-strand conformational polymorphism loci in two white pine blister rust populations from eastern white pine plantations

\begin{tabular}{lccccccc}
\hline Population & No. of haplotypes & Haplotypic diversity $^{\mathrm{a}}$ & $P$ & $\mathrm{I}_{\mathrm{A}}{ }^{\mathrm{b}}$ & $P$ & $\bar{r}_{d}{ }^{\mathrm{c}}$ \\
\hline Saint-Cyprien & 54 & 0.972 & 0.270 & 0.017 & 0.370 & 0.002 & 0.370 \\
Saint-Georges & 42 & 0.970 & 0.250 & 0.013 & 0.440 & 0.002 & 0.440 \\
\hline
\end{tabular}

a Probability that two individuals taken at random have different haplotypes.

${ }^{\mathrm{b}}$ Index of association (48).

${ }^{\mathrm{c}}$ Correlation coefficient of distance, which has a maximum value of 1 if there is complete linkage and 0 in the absence of linkage (Multilocus 1.2 documentation).

TABLE 3. Analysis of molecular variance for six random amplified polymorphic DNA and three single-strand conformational polymorphism markers in two Cronartium ribicola populations from eastern white pine plantations in Quebec

\begin{tabular}{lcccccc}
\hline Source & df & \multicolumn{1}{c}{ SS $^{\mathrm{a}}$} & MS $^{\mathrm{b}}$ & Variance & $\Phi_{s t}{ }^{\mathrm{c}}$ & $P_{\text {value }}{ }^{\mathrm{d}}$ \\
\hline Among plantations & 1 & 6.775 & 6.775 & 0.058 & 0.030 & 0.010 \\
Within plantation & 175 & 340.293 & 1.945 & 1.945 & $\ldots$ & $\ldots$ \\
\hline
\end{tabular}

a Sum of squared distances (9).

${ }^{\mathrm{b}}$ Mean squared distances (9).

${ }^{\mathrm{c}} F_{\text {st }}$ analog (9).

d Probability determined by 500 randomizations. 
Aeciospores and basidiospores are the most likely spore types involved in long-distance dispersal. Although aeciospores cannot reinfect the pine host and cannot generate multiple generations on the telial host, they are produced abundantly and are UV and drought resistant. Still, fairly steep disease gradients have been observed from inoculum sources of pine in western gall rust (aeciospore source) and around oak sources in C. quercuum $\mathrm{f}$. sp. fusiforme (basidiospore source), suggesting that the spores do not disperse massively over long distances (46). But it may be that the tail end of the spore distribution is long, resulting in long-distance dispersal of lower inoculum concentrations. This would explain why the eradication of alternate hosts often failed as a control measure.
The distance of dispersal of primary inoculum has been speculated upon and several values have been proposed. The Ribes spp. eradication program was based on the assumption that inoculum was disseminated only locally $(<1.6 \mathrm{~km})$ and that eliminating the telial host would control the disease $(32,33)$. Eradication under some conditions can reduce rust incidence, but evidence showed that basidiospores could be dispersed as far as $14 \mathrm{~km}$ away from their source (52). Our results are in agreement with the relatively long-distance dispersal of basidiospores.

The relationship between genetic and geographic distances previously was investigated at a much larger scale, comparing populations that were separated by several hundred kilometers (8). The hypothesis of isolation by distance in eastern populations
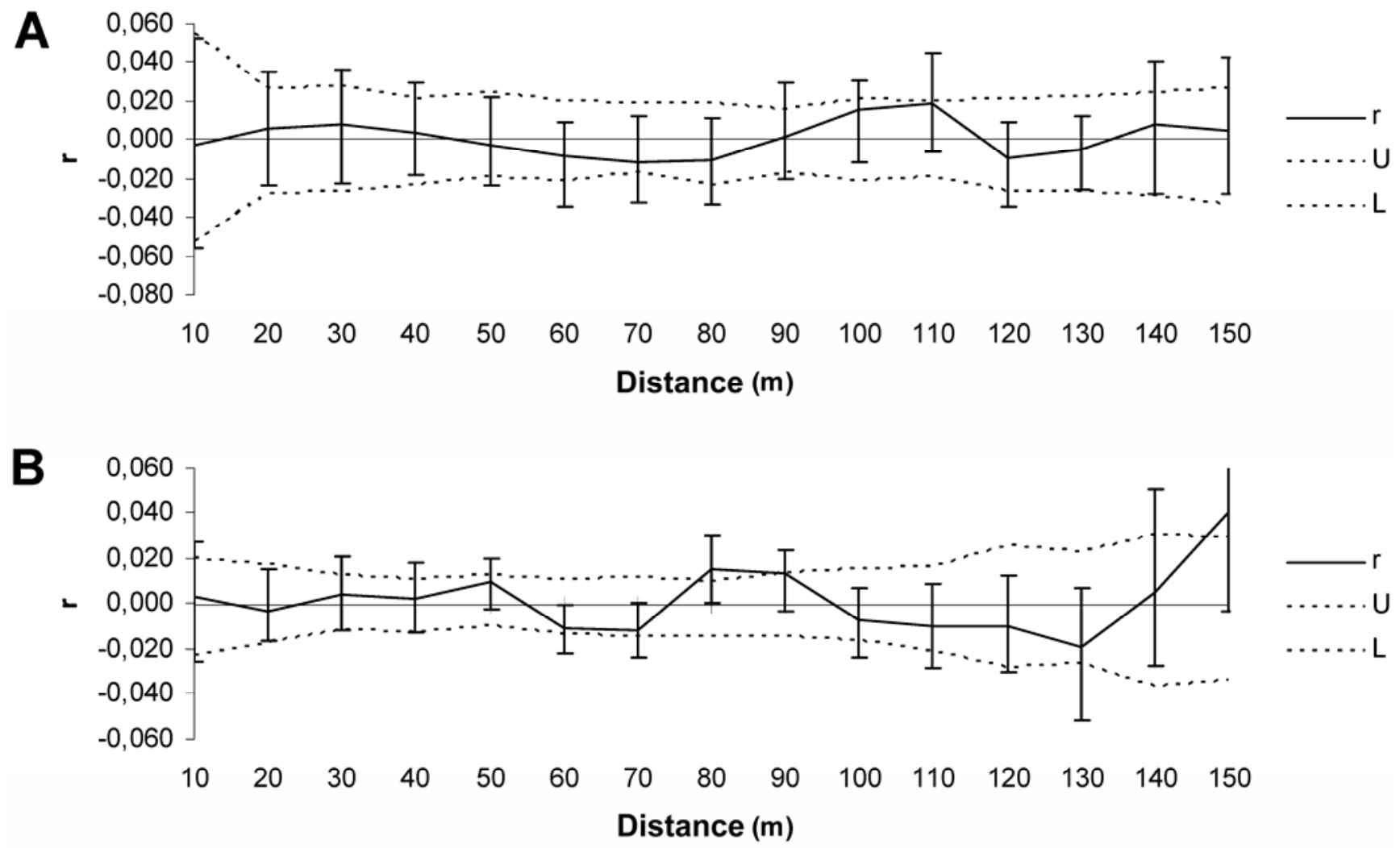

Fig. 1. Spatial correlogram for all pairwise comparison within the A, Saint-Cyprien and B, Saint-Georges plantations among samples in 15 distance classes of $10 \mathrm{~m}$; $r$ is the multilocus correlation coefficient, $\mathrm{U}$ and $\mathrm{L}$ are upper and lower $95 \%$ interval limits (50).

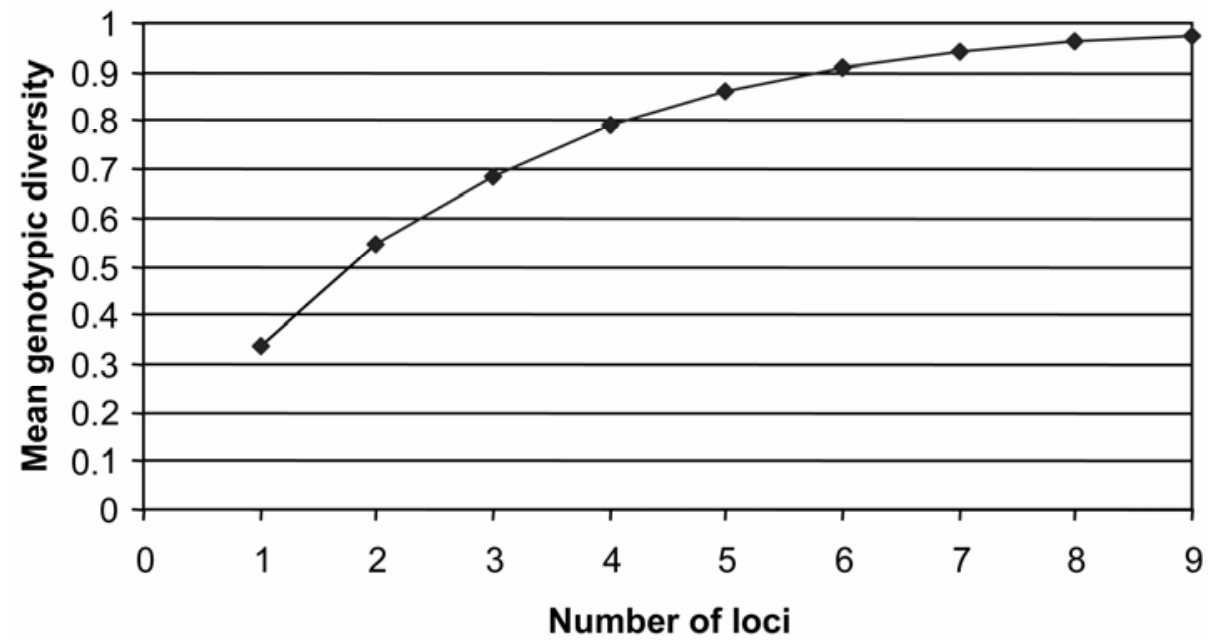

Fig. 2. Plot of number of loci versus haplotypic diversity for six random amplified polymorphic DNA and three single-strand conformational polymorphism loci in two Cronartium ribicola populations. The maximum genotypic diversity is 1 . 
of $C$. ribicola was rejected because no correlation was found between genetic and geographic distances. In spite of the high level of haplotypic diversity observed in the current study, genetic differentiation was very small among the two populations. This suggests that gene flow between these populations takes place and homogenizes allele frequencies. It also is possible that historical gene flow is responsible for this low level of genetic differentiation. However, the sites where sampling was conducted were fairly recent conversions from agricultural fields into pine plantations. Thus, the infections on the pine hosts most likely are the result of recent migration events.

This result is slightly different from that observed in $C$. quercuum $\mathrm{f}$. sp. fusiforme, where four metapopulations were found in North America (31). A main difference between these pathosystems is that $C$. quercuum $\mathrm{f}$. sp. fusiforme is native whereas white pine blister rust is an exotic pathogen. It is possible that $C$. quercuum f. sp. fusiforme has co-evolved with its pine hosts and adapted locally to host genotypes and environments. The very large genetic diversity observed in that pathogen and in the related $C$. quercuum f. sp. banksiana would be consistent with this scenario (16,31). In contrast, $C$. ribicola has a very narrow genetic basis, as was shown by restriction fragment length polymorphism, isozymes, RAPD, and PCR-SSCP $(10,12,30,54)$, and has not had a long history of co-evolution with the North American pine hosts, thus reducing the potential for local adaptation.

It may be possible that new MLHs could have been identified with a larger number of markers, but our analysis indicates that only negligible increases in genotypic diversity could be expected. The plot of number of loci versus haplotypic diversity appears to plateau and only a small increase in diversity was observed between the eighth and ninth loci. It is unlikely that the conclusions of this study would be different with a larger number of loci.

Although our results rely upon only two sites, we chose to perform intensive sampling of these sites instead of sampling fewer individuals over several sites. Our decision was based upon the fact that genetic composition appears to be very similar over a large number of eastern North American $C$. ribicola populations $(8,17)$. Thus, our assumption is that our results are representative of the eastern epidemiological unit. However, it remains to be seen whether or not western populations possess similar parameters with regard to recombination and spatial distribution. A longer growing season and the potential for a higher ratio of asexual versus sexual cycles could result in a different fine-scale population structure.

\section{ACKNOWLEDGMENTS}

We thank C. Coulombe for helping in sample collection, R. Lavallée for valuable discussions, A. Martellini for technical help, I. Lamarre for editorial suggestions, and two anonymous reviewers for their helpful comments.

\section{LITERATURE CITED}

1. Bagley, M. J., Medrano, J. F., and Gall, G. A. E. 1997. Polymorphic molecular markers from anonymous nuclear DNA for genetic analysis of populations. Mol. Ecol. 6:309-320.

2. Blodgett, J. T., and Sullivan, K. F. 2004. First report of white pine blister rust on Rocky Mountain bristlecone pine. Plant Dis. 88:311.

3. Bourassa, M., Bernier, L., Milligan, B. G., and Hamelin, R. C. 1998. Effect of host sympatry on the genetic structure of poplar leaf rust. Pages 65-70 in Proc. First IUFRO Rust of Forest Trees Conf. Saariselka, Finland. Finnish For. Res. Inst. Res. Pap. 712.

4. Burt, A., Carter, D. A., Koenig, G. L., White, T. J., and Taylor, J. W. 1996. Molecular markers reveal cryptic sex in the human pathogen Coccidioides immitis. Proc. Natl. Acad. Sci. USA 93:770-773.

5. Craigie, J. H. 1927. Discovery of the function of the pycnia of the rust fungi. Nature 120:765-767.

6. Devey, M. E., Delfino-Mix, A., Kinloch, B. B., Jr., and Neale, D. B. 1995. Random amplified polymorphic DNA markers tightly linked to a gene for resistance to white pine blister rust in sugar pine. Proc. Natl. Acad. Sci.
USA 92:2066-2070.

7. Draper, M. A., and Walla, J. A. 1993. First report of Cronartium ribicola in North Dakota. Plant Dis. 77:9.

8. Et-touil, K., Bernier, L., Beaulieu, J., Bérubé, J. A., Hopkin, A., and Hamelin, R. C. 1999. Genetic structure of Cronartium ribicola populations in eastern Canada. Phytopathology 89:915-919.

9. Excoffier, L., Smouse, P. E., and Quattro, J. M. 1992. Analysis of molecular variance inferred from metric distances among DNA haplotypes: Application to human mitochondrial DNA restriction data. Genetics 131:479-491.

10. Gitzendanner, M. A., White, E. E., Foord, B. M., Dupper, G. E., Hodgskiss, P. D., and Kinloch, B. B., Jr. 1996. Genetics of Cronartium ribicola. III. Mating system. Can. J. Bot. 74:1852-1859.

11. Groth, J. V., and Roelfs, A. P. 1982. Effect of sexual and asexual reproduction on race abundance in cereal rust fungus populations. Phytopathology 72:1503-1507.

12. Hamelin, R. C. 1996. Genetic diversity between and within cankers of the white pine blister rust. Phytopathology 86:875-879.

13. Hamelin, R. C. 2000. Molecular epidemiology of tree pathogens. Pages 375-393 in: Molecular Biology of Woody Plants, Vol. 2. S. M. Jain and S. C. Minocha, eds. Kluwer Academic Publishers, Dordrecht, The Netherlands.

14. Hamelin, R. C. 2004. Exotic and native rust pathosystems: A population genomics approach. (Abstr.) Phytopathology 94(suppl.):S127.

15. Hamelin, R. C., Beaulieu, J., and Plourde, A. 1995. Genetic diversity in populations of Cronartium ribicola in plantations and natural stands of Pinus strobus. Theor. Appl. Genet. 91:1214-1221.

16. Hamelin, R. C., Doudrick, R. L., and Nance, W. L. 1994. Genetic diversity in Cronartium quercuum f. sp. fusiforme on loblolly pines in southern U.S. Curr. Genet. 26:359-363.

17. Hamelin, R. C., Dusabenyagasani, M., and Et-touil, K. 1998. Fine-level genetic structure of white pine blister rust populations. Phytopathology 88:1187-1191.

18. Hamelin, R. C., Hunt, R. S., Geils, B. W., Jensen, G. D., Jacobi, V., and Lecours, N. 2000. Barrier to gene flow between eastern and western populations of Cronartium ribicola in North America. Phytopathology 90:1073-1078.

19. Hawksworth, F. G. 1990. White pine blister rust in New Mexico. Plant Dis. 74:938

20. Hummer, K. E. 2000. History of the origin and dispersal of white pine blister rust. HortTechnology 10:515-517.

21. Hunt, R. S. 1985 Experimental evidence of heterothallism in Cronartium ribicola. Can. J. Bot. 63:1086-1088.

22. Hunt, R. S., and Meagher, M. D. 1989. Incidence of blister rust on "resistant" white pine (Pinus monticola and P. strobus) in coastal British Columbia plantations. Can. J. Plant Pathol. 11:419-423.

23. Johnson, D. W., and Jacobi, W. R. 2000. First report of white pine blister rust in Colorado. Plant Dis. 84:595.

24. Kasanen, R., Kaitera, J., and Hantula, J. 2000. The genetic composition of Peridermium pini and Cronartium flaccidum cankers on Scots pine as revealed by two multi-allelic loci. For. Pathol. 30:221-230.

25. Keane, R. E., and Arno, S. F. 1993. Rapid decline of whitebark pine in western Montana: Evidence from 20-year remeasurements. West. J. Appl. For. 8:44-47.

26. Kinloch, B. B., Jr., and Dulitz, D. 1990. White pine blister rust at Mountain Home Demonstration State Forest: A case study of the epidemic and prospects for genetic control. U.S. Dep. Agric. For. Serv. Pac. Southwest Res. Stn. Res. Pap. 204. Berkeley, CA.

27. Kinloch, B. B., Jr., and Dupper, G. E. 1987. Restricted distribution of a virulent race of the white pine blister rust pathogen in the western United States. Can. J. For. Res. 17:448-451.

28. Kinloch, B. B., Jr., and Dupper, G. E. 2002. Genetic specificity in the white pine-blister rust pathosystem. Phytopathology 92:278-280.

29. Kinloch, B. B., Jr., Sniezko, R. A., Barnes, G. D., and Greathouse, T. E. 1999. A major gene for resistance to white pine blister rust in western white pine from the Western Cascade Range. Phytopathology 89:861-867.

30. Kinloch, B. B., Jr., Westfall, R. D., White, E. E., Gitzendanner, M. A., Dupper, G. E., Foord, B. M., and Hodgskiss, P. D. 1998. Genetics of Cronartium ribicola. IV. Population structure in western North America. Can. J. Bot. 76:91-98.

31. Kubisiak, T. L., Roberds, J. H., Spaine, P. C., and Doudrick, R. L. 2004. Microsatellite DNA suggests regional structure in the fusiform rust fungus Cronartium quercuum $\mathrm{f}$. sp. fusiforme. Heredity 92:41-50.

32. Maloy, O. C. 1997. White pine blister rust control in North America: A case history. Annu. Rev. Phytopathol. 35:87-109.

33. Martin, J. F. 1944. Ribes eradication effectively controls white pine blister rust. J. For. 42:255-260.

34. McDermott, J. M., and McDonald, B. A. 1993. Gene flow in plant pathosystems. Annu. Rev. Phytopathol. 31:353-373. 
35. McDonald, B. A. 1997. The population genetics of fungi: Tools and techniques. Phytopathology 87:448-453.

36. Milgroom, M. G. 1996. Recombination and the multilocus structure of fungal populations. Annu. Rev. Phytopathol. 34:457-477.

37. Milgroom, M. G., and Fry, W. E. 1997. Contributions of population genetics to plant disease epidemiology and management. Adv. Bot. Res. 24:1-29.

38. Milgroom, M. G., and Lipari, S. E. 1995. Spatial analysis of nuclear and mitochondrial RFLP genotypes in populations of the chestnut blight fungus, Cryphonectria parasitica. Mol. Ecol. 4:633-642.

39. Nei, M. 1987. Molecular Evolutionary Genetics. Cambridge University Press, New York.

40. Nicole, M. C., Lavallée, R., and Hamelin, R. C. 1998. Identification of insects involved in white pine blister rust spermatization by PCR. (Abstr.) Phytopathology 88(suppl.):S67.

41. Pei, M. H., and Ruiz, C. 2000. AFLP evidence of the distinctive patterns of life-cycle in two forms of Melampsora rust on Salix viminalis. Mycol. Res. 104:937-942.

42. Ragazzi, A., Moricca, S., and Dellavalle, I. 1998. Disease gradient of Cronartium flaccidum on its intermediate host Vincetoxicum hirundinaria. J. Plant Dis. Prot. 105:58-63.

43. Reinhart, D. P., Haroldson, M. A., Mattson, D. J., and Gunther, K. A. 2001. Effects of exotic species on Yellowstone's grizzly bears. West. North Am. Nat. 61:277-288.

44. Samils, B., Stepien, V., Lagercrantz, U., Lascoux, M., and Gullberg, U. 2001. Genetic diversity in relation to sexual and asexual reproduction in populations of Melampsora larici-epitea. Eur. J. Plant Pathol. 107:871-881.

45. Schmidt, R. A., Allen, J. E., Belanger, R. P., and Miller, T. 1995. Influence of oak control and pine growth on fusiform rust incidence in young slash and loblolly pine plantations. South. J. Appl. For. 19:151-156.

46. Schmidt, R. A., Carey, W. A., and Hollis, C. A. 1982. Disease gradients of fusiform rust on oak seedlings exposed to a natural source of aeciospore inoculum. Phytopathology 72:1485-1489.
47. Smith, J. M. 1993. The role of sex in bacterial evolution. J. Hered. 84:326-327.

48. Smith, J. M., Smith, N. H., O'Rourke, M., and Spratt, B. G. 1993. How clonal are bacteria? Proc. Natl. Acad. Sci. USA 90:4384-4388.

49. Smith, J. P., Hoffman, J. T., Sullivan, K. F., Van Arsdel, E. P., and Vogler, D. 2000. First report of white pine blister rust in Nevada. Plant Dis. $84: 594$.

50. Smouse, P. E., and Peakall, R. 1999. Spatial autocorrelation analysis of individual multiallele and multilocus genetic structure. Heredity 82:561573.

51. Spaulding, P. 1911. The blister rust of white pine. U.S. Dep. Agric. Bur. Plant Ind. Bull. No. 206.

52. Van Arsdel, E. P. 1958. Smoke movement clarifies spread of blister rust from Ribes to distant white pine. Am. Meteorol. Soc. Bull. 39:442443.

53. Vogler, D. R., and Charlet, D. A. 2004. First report of the white pine blister rust fungus (Cronatium ribicola) infecting whitebark pine (Pinus albicaulis) and Ribes spp. in the Jarbidge Mountains of Northeastern Nevada. Plant Dis. 88:772.

54. White, E. E., Foord, B. M., and Kinloch, B. B., Jr. 1996. Genetics of Cronartium ribicola. II. Variation in the ribosomal gene cluster. Can. J. Bot. 74:461-468.

55. Xu, J., Desmerger, C., and Callac, P. 2002. Fine-scale genetic analyses reveal unexpected spatial-temporal heterogeneity in two natural populations of the commercial mushroom Agaricus bisporus. Microbiology 148:1253-1262.

56. Yu, X., Ekramoddoullah, A. K. M., Sturrock, R. N., and Zamani, A. 2001 The antigen reactive to an anti-white pine blister rust fungal monoclonal antibody (Mab 7) is a homolog of $70-\mathrm{kDa}$ heat shock proteins (a BiP protein). Mycologia 93:1174-1185.

57. Ziller, W. G. 1974. The tree rusts of western Canada. Can. For. Serv. Pac. For. Res. Cent. Publ. No. 1329. Victoria, BC, Canada. 